\title{
Concepts of Extrasensory Potential Telepathy in the Literature of Pandit Shriram Sharma Acharya
}

\author{
Jwalant R. Bhavsar ${ }^{*}$
}

${ }^{1}$ Research Scholar, Department of Clinical Psychology, Dev Sanskriti Vishwavidyalaya, Haridwar, India *Corresponding author email: jwalant.bhavsar@dsvv.ac.in

https://doi.org/10.36018/dsiij.v18i.228

\begin{abstract}
Telepathy is considered a unique supernatural phenomenon that falls under the classification of Extra Sensory Potentials. The western world has developed several concepts and theories based on the assumptions and experiences of several learned individuals. Here, the present study was based on eastern philosophies written and practiced by Pandit Shriram Sharma Acharya Ji, who is the most recent legend with a perfect balance of scientific perspective towards spirituality. His establishments and achievements are unique as they all despite his physical absence consistently thrive to blend both the extreme ends. This research aims to present a concept of telepathy from the viewpoint of Pandit Shriram Sharma Acharya Ji. Telepathy is renowned fashionably for its misconceptions as well as scientific inexplicability. The potential classified as extrasensory exists and is experienced substantially but when it comes to controlled experimentation, it is very difficult to carry out as they are dependent on individuals' spiritual life and journey. Pandit Shriram Sharmaji was a spiritual scientist who has throughout his life experimented with spirituality on his life. His concepts are not only mere assumptions but filled with deep understanding, scientific references, and research. After the indepth study of the literature of Pandit Shriram Sharmaji, which includes his huge volumes of complete works (Vangmays) and other spiritual and scientific texts, it was found that the telepathic capacities, through the proper practice of various spiritual techniques and personality refinements, can also be acquired and enhanced too. This opens up several new areas of research in the field of Extrasensory potential, especially Telepathy.
\end{abstract}

Keywords. Extrasensory Potential, Telepathy, Pandit Shriram Sharma Acharya, Human Brain, Spiritual Practices, Self-Refinement

\section{INTRODUCTION}

At some instance of life, we all must have experienced or heard that someone, let's say Mr. X was strongly thinking about Mr. $\mathrm{Y}$ and surprisingly, Mr. Y suddenly shows up maybe personally or through a phone call saying that somehow, he had a strong feeling to get in touch with Mr. X. This could have happened with us or maybe we have heard someone say it. Normally, we call this instance of telepathy and probably do not take it seriously thinking that it might be a coincidence or maybe real telepathy that normally happens. 
Imagine, if we can communicate through our mental capacities without the use of psychical senses or objects. The world is vast, but its secrets lie in very minute things. Small things when united signify the existence of larger entities. A human body cannot exist if the smallest component called 'cells' do not bind themselves together working in perfect synchronization. A small atom when parted systematically can lead to provide light to the whole city or maybe light it up to fumes. The existence prevails in the smaller entities, and they reflect themselves through the larger entities.

How small a human brain can be and inside it how small a brain cell or maybe the components of neurotransmitter can be. All this mesmerizing existence prevails only to show that nature has so much to offer and teach us and there is so much that is beyond our knowledge.

The human brain is one such component of nature that we are yet to decipher. Most of us know what we know, and we also know what we don't know, but imagine if there can be concepts that we don't know and we don't even know that we don't know.

The walls of ignorance can veil the capacities hidden within us. Some say the human brain has developed and some say it has evolved, in any of the cases it is important that the development is existentially visible but only in the physical plains.

What about the development of non-physical capacities? We have enriched in terms of knowledge about everything around us, but what about the knowledge that floats within us. The capacities that we have by default are hidden and yet to be explored. These mental capacities are prevailing within human existence. The reason why this thought can sustain argument is that several living beings have these capacities through which they can communicate without using any senses or any medium of contact (1)

There are examples where animals have exhibited the capacity of telepathy. Dr Rupert Sheldrake investigated pet's behavior and found that in 50\% of dog-owning households and $30 \%$ of those with cats, the pet animals were found to anticipate the arrival of a family member." In another finding, he found that 177 cases of dogs responding to the death or suffering of their absent masters or mistresses, mostly by howling, whining, or whimpering, and 62 accounts of cats showing similar signs of distress (2).

A naturalist Willian Long who, in 1919 wrote a book that described the behavior of a pack of wolves that he had followed in Canada. He found separated members of wolf packs remained in contact with each other and responded to each other's activities while many miles apart (3).

In 2001, on 26th January when there was a massive earthquake in Gujarat, India people observed that minutes before the earthquake happened, the bird suddenly left their nests and trees and started to fly around in the sky making lots of noises. The dogs as well started barking intensively. All these capacities that animals have (4) can be searched for in human beings as well.

This research aims to present a perspective of telepathy from the viewpoint of Pandit Shriram Sharmaji. Telepathy although considered as a new concept that seems to be coined in the western world has originally been in practice in India and the eastern world since a very ancient time. There are instances where seers and sages have communicated telepathically with other people and animals. Documented records of various people have been observed about the same. Swami Yogananda presented the most recent 
documentation in his book named "Autobiography of a Yogi”.

In Chapter 10, Swami Yogananda mentions his meeting with His Guru Swami Yukteshwar Ji where he writes, "the saint is magnetically drawing me to him!" The instance was when he sought his Guru desperately and even while passing through him and not able to recognize him, he got propelled towards him (5). In ancient Indian literature, there are several other such instances where telepathic communication is done not only from one source to one receiver but multiple recipients.

Telepathy, term was coined in 1882 by the classical scholar names Frederic W. H. Myers, a founder of the Society of Psychic Research (6). Earlier it was known as thought-transfer until Myers coined the word. The literal meaning of the word telepathy is distant feeling or perception. The word originated from the Greek language where 'Tele' means distant and the word 'pathy' originates from 'pathos', which means feeling, perception, or experience. Although, the concept lacks strong scientific publications to prove itself as a phenomenon still it has its prevalence. Besides, as Carl Jung quotes, "I shall not commit the fashionable stupidity of regarding everything that I cannot explain as a fraud" gives scope of further research (7).

Although Telepathy studies are not much done, there are instances, experiences and experiments that define its existence opening up scope of scientific studies.

\section{TELEPATHY}

Telepathy is defined as the transference of thoughts or feelings between two or more subjects without the use of senses or other physical objects. It is clearly said to be a mental capacity that is unique and not so prevalent. Modern parapsychological researchers have conducted several experiments to understand and prove this wonderful capacity of the human mind. The origin of the concept of telepathy in the western world dates back to the later $19^{\text {th }}$ Century when the physical sciences made significant advances and scientific concepts were applied to mental phenomena with the hope that this would help understand paranormal phenomena. The modern concept of telepathy emerged in this context (8).

In parapsychology, telepathy is considered to be a form of ESP, which means Extra Sensory Perception. It is often categorized as similar to precognition or clairvoyance. The most well know experiments that have been carried out till now are Zener Cards and Ganzfield Experiment (9).

Several types of telepathies are classified by modern-day parapsychologists. Mainly four types have been defined which are

1. Latent Telepathy is also known as deferred telepathy in which the transfer of information is done without the use of senses with an observable time lag between transmission and reception.

2. Retro cognitive, precognitive and intuitive telepathy is the transfer of information about the part past, future, or present state of an individual's mind to another individual (10).

3. Emotive Telepathy, which is also known as remote influence or emotional transfer. It is a process of transferring kinesthetic sensations through altered states (11).

4. Superconscious telepathy involves tapping into superconscious to access the collective wisdom of the human species for knowledge (12).

A Ganzfield experiment is a method used in Psi Studies. It has been claimed that it has the potential to verify for extrasensory perceptions (ESP) prevail in an individual (13). These 
experiments are among the most recent in parapsychology for testing telepathy.

It was originally introduced into experimental psychology due to the experiments of the German psychologist Wolfgang Metzger on the perception of a homogenous visual field. In the early 1970s, Charles Honorton had been investigating ESP and dreams at the Maimonides Medical Center and began using the Ganzfield technique to achieve a state of sensory deprivation in which he hypothesized that psi could work. Honorton believed that by reducing the ordinary sensory input, psi conductive states may be enhanced and psi-mediated information could be transmitted. Since Honorton and Sharon Harper published the first full experiment in 1974 in the Journal of the American Society for Psychical Research, the Ganzfeld has remained a mainstay of parapsychological research (14).

Originally in a Ganzfeld experiment, the "receiver" sits in a comfortable chair wearing a headphone with halved ping-pong balls over the eyes and a red light shone on the receiver and placed in a room. In the headphones of the receiver white or pink noise (static) is played. The receiver for half an hour is kept in this state of mild sensory deprivation. During this time a randomly chosen target is observed by the sender and tries to mentally send this information to the receiver after 30 mins the receiver speaks out loud and, describes what is being seen by him or her. The whole process is being recorded by the experimenter (who is blind to the target) either by recording onto tape or by taking notes and later help the receiver at the time of the judging procedure in which the receiver is given a set of possible targets after taken out from the Ganzfeld state, from which they have to select one which is most resembled the images they witnessed during the experiment (15).
In 1970, Dr. Stanley Krippner and Dr. Montague Ullman conducted a study that was designed to investigate telepathic effects in dreams. A single Subject, who had previously been successful in a similar study at another laboratory, spent 8 nights at the Maimonides Dream Laboratory. On each night, a target (art print) was randomly selected by a staff member (agent) after the subject was in bed. The agent spent the night in a distant room, attempting to influence the subject's dreams telepathically, once the monitoring experimenters signaled that a dream period had begun. At the end of each dream period (detected by electroencephalogram- electro-oculogram monitoring), the subject was awakened by the experimenters and the dream report was elicited and tape-recorded. Only the agent was aware of the target content, and he remained in his room throughout the night. Blind evaluations of targetdream correspondences by both subject and an outside judge produced statistically significant results supporting the telepathy hypothesis (16).

Thus, telepathy is a known concept that is in existence yet needs to be pondered upon. There are several perspectives about the way telepathy can be practiced and experimented with.

\section{PANDIT SHRIRAM SHARMA LITERATURE}

Pandit Shriram Sharma Ji (Acharyashri) was born on 20th September 1911. During this journey of 79 years, he had remarkable achievements and establishments. He was born in a village named Awalkheda near Agra in Uttarpradesh. His whole life was devoted to austere penance for clearing the way for the emergence of a new era of universal peace, harmony, and goodwill that could be linked with an era of descent of Heavens on the Earth.

At the age of fifteen, his Spiritual Guru, a Himalayan Yogi, Sarveshwaranandji had appeared 
in his vision during the worship in the astral body. As per Sarveshwaranandji's instruction, Pandit Shriram performed twenty- four mahapurashcarañas (2.4 million recitations) of Gayatri Mantra each for twenty-four years. $\mathrm{He}$ visited the Himalayas four times for higher spiritual attainments. He also took part in the nonviolent struggle for India's independence as a volunteer; went to jail several times as part of the freedom struggle and embarked upon the task of social and moral upliftment through spiritual means with the blessings of Mahatma Gandhi.

A sage, a visionary, a social reformer, Acharyashri propounded 100 points YugNirmanYojna for social, intellectual, and spiritual evolution. $\mathrm{He}$ lived a simple, disciplined life full of devout austerity, visited the Himalayas several times and attained spiritual eminence and foresight.

The Gayatri Pariwar fraternity, Shantikunj Ashram (the headquarters of Gayatri Pariwar), an academy for moral and spiritual awakening; Brahmavarchas Research Institute which strives to synthesize science with spirituality, Akhand Jyoti Sansthan, Mathura, Gayatri Tapobhumi, Mathura and thousands of social reform and sadhana centres (Shakti Peeths) around the globe are other grand contributions of Yugrishi Pandit Shriram Sharma Acharya to the modern world.

Millions of people in India and abroad have been kindled with missionary enthusiasm and zeal to transform their own lives and society as a whole in the light of Yugrishi's messages. He voluntarily shed his physical sheath on Gayatri Jayanti, June 2, 1990, but even after his physical departure from the scene, the Mission spread to global dimensions and 41 AshwamedhYagyas (32 in India, 9 abroad including U.K, U.S.A, Canada, Australia, and South Africa) were performed to carry forward the tasks initiated by the Yugrishi.
Acharya Shri translated the entire Vedic Vangmaya in lucid Hindi with eloquent comprehensive introductions and accomplished the feat of writing more than 2400 enlightening books in Hindi on all aspects of life. His writings encompass far-reaching, sagacious and feasible solutions to the innumerable problems of today. He wrote on topics like Economics, Psychology, Medical Science, Life Management, Emotional Balance, Spirituality, Technology and various others.

The first book that he wrote in 1942 was named 'Main Kya Hoon?' translated later in English entitled "What am I?" He had given the concepts on the purpose of life and the ways through which the gifted human existence can be utilized wisely. In around 1965, he coined the term "Scientific Spirituality". He had been given the vision to transform the world and had a deep understanding that the world can only be transformed if every individual takes responsibility to transform him/herself.

He also understood that all human beings are driven by their own strong beliefs that are designed through the experiences of life or maybe the suggestions given to the person that is in an idolizing position. Acharya Shri thus initiated the "Thought Revolution Movement" where he started writing books and delivering lectures that inspired people towards righteous thinking. He understood that the base on which the thoughts can be transformed can be religion but at the same time, he understood that religiosity if misinterpreted can lead to staunch resistance for acceptance of another person's life. Thus, he started advocating Scientific Spirituality where he metaphorically said that science is blind without spirituality as it can miss the direction and propel towards destruction. At the same time, spirituality is lame without science as it can lead to misconceptions 
and blind beliefs. With the same concern, he also established a research centre in the year 1979 where he advocated the research of spiritual philosophies and rituals on a scientific basis.

A spiritually enlightened mind is said to be a source of divine potential. Hidden beneath the core of the conscious mind, there lie the prodigious powers of the unconscious mind. Activation of the subtle centers in the brain and the endocrine system helps expression of miraculous powers of the inner mind and the manifestation of its extrasensory faculties in the gross world. Clairvoyance, precognition, knowledge of the hidden of the unseen, realization of the distant past or the future as happening in the present, extrasensory perceptions beyond the barriers of space-time constraints, are among the much talked of supernatural experiences. These also constitute the major cause of common curiosity on the one front and the focus of the meticulous scientific inquisitiveness on the other (17).

The major literary works of Pandit Shriram Sharma Acharyaji consist of almost all texts prevalent in the spiritual fraternity. His literary journey started during the struggle for freedom when he started writing inspirational poems for other freedom fighters. He gave his poems in various newspapers through which people used to read them. He also assisted Shri Krishnadatt Paliwali $\mathrm{Ji}$, the editor of a newspaper named "Sainik" around 1935. On the occasion of Vasant Panchmi, 1938, he started his magazine titled "Akhand Jyoti". Due to the lack of information and resources, he took a pause and re-launched the magazine from January 1940. Since then, this magazine has been the source of information and inspiration for millions of people around the globe till today.
He translated the four Vedas, 108 Upanishads and Puranas. He had a deep quest and understanding for the scientific aspects of Spirituality, which he expressed in his books and writings. He deeply discussed the concepts of extra-sensory potentials of human beings in his various articles published in Akhand Jyoti as well as in several books.

The depletion of thoughts only leads to downfall and destruction. The mishap this world has witnessed till now is due to the deteriorated level of thoughts. The thoughts that are useless and selfcentered lead to the downfall of mankind first at an individual level and then at the universal level altogether. Thus, Pandit Shriram Sharmaji focused on uplifting the level of thoughts through the thought revolution movement. Pandit Shriram Sharmaji's literature is a live example of thoughtprovoking text that compels a person to start thinking about the whole universe as the basis of his/her existence. The scientific and spiritual concepts and theories presented by Pandit Shriram $\mathrm{Ji}$ are unique and farsighted with an intention to advocate and balance the major two aspects of human life that is humans' internal existence and the external entity. He has written on several concepts touching human life including concepts that the current world knows as paranormal or parapsychological. He has written several books and articles on extra-sensory potentials of the mind conveying the deeper science of extrasensory capacities of human beings. All the writings were not only mythical but also scientific.

\section{Telepathy in Book 'Extra Sensory Potentials of Mind'}

In one of the books that he wrote which is titled "Extra Sensory Potentials of Mind," he mentioned that telepathy is real and feasible (17). He writes, "With increasing instances of scientific verification, it is becoming clearer that there does exists a subliminal linkage of consciousness that 
makes the process of distant communication between humans feasible without any medium or telecommunication instruments. The field of spirituality mentions a great deal of such extrasensory processes. Ancient Indian scriptures describe these instances with associated sādhanās and their attainments in great detail. The modern science has also approved the possibility of these potentials under the headings telepathy, thoughttransfer, thought-reading, etc" (17).

\section{Experiment of Popova-group}

Acharaya ji has given an example of a scientific experiment conducted by Russian scientists also known as "Popova-group" to verify telepathy. Kaminski and Nikolai were one of the first pairs to be the participants of this experiment in which they were placed at two different labs approximately 800 kilometers apart.

Kaminski was prepared to be the sender of the messages whereas Nikolai was at the receiving end of the messages being completely unaware of when and from where will he be receiving the messages. Kaminski in Moscow was instructed to silently focus on his thoughts and send those to Nikolai. Nikolai in Leningrad, on the other end, was calmly sitting in a soundproof lab to receive the "latent messages" with the EEG electrodes on his head to continuously record his brain impulses. The readings were set to be automatic and were administered in an adjacent room.

The scientists from both the labs across different cities confirmed the timings of the changes observed in the EEG recordings once the transmission process began. There were significant changes in EEG characteristics and in alpha wave patterns in Nikolai's EEG readings indicating reception of the messages at his end. Later on, several such experiments were conducted in different labs confirming that the results were best observed in the case of people with good concentration of mind but also in the case of subjects with a serene attitude and austere nature. Some experiments were also conducted with subjects who were slightly short-tempered and of cruel nature and their EEG recordings had hardly shown any reception of the messages. A similar experiment was conducted on twin brothers in Philadelphia by two ophthalmologists in whom results similar to Kaminski and Nikolai's experiment were obtained. The results were reported in "Herald Tribune" of New York, under the article "Twins Prove Electronic Extrasensory Perception".

\section{Possible mechanism of Popova-group experiment}

Acharaya ji has explained this phenomenon using the radio transistor analogy. Since the brain waves are electrical impulses of specific wavelengths, he says, these are received by the field of compatible currents or impulsive flow. As the radio transistor must be attuned to a specific bandwidth to receive specific signals, similarly the state of the receptor's brain/ mind determines the reception of thought waves. The thinking of a person is affected by factors such as psychological nature, inner tendencies, and character of the person which in turn affects his thought waves.

It has been observed in subliminal communication during telepathy that in the case of pair of participants with similar deeper emotions, and similar characters the changes in the brain impulses of the sender result in corresponding variations in the receiver's brain impulses too.

According to the laws of physics, those sound waves or energy is never lost. So it can be understood that the waves emitted by us while speaking whether audible or subtler are a form of energy that continuously moves and connects with thoughts or waves of similar characteristics 
forming a dense energy field of thoughts termed as "ideosphere". If we can refine our thoughts and emotions, our aspirations, attitude, and inner state and empower ourselves enough then we would be able to attract and receive thought waves of great minds from the domains of ideosphere and benefit ourselves with great ideas and inspirations.

\section{As per Dr. Penfield and Dr. Gasper}

Furthermore, in their book "Epilepsy and the Functional Anatomy of the Human Brain" Dr. Penfield and Dr. Gasper have explained the connection between cosmic (thought) waves and the human mind.

As per their reports, Albert Einstein's brain used to continuously emit alpha waves (indicating sharp alertness of mind) even when he was deeply engrossed in solving complicated problems of mathematics or was asleep. It indicated that Einstein's mind has the capacity to receive cosmic signals almost all the time despite being in different types of daily activities. As per Dr. Penfield, Einstein's mind has exceptional alacrity and trenchancy which unconsciously trained to receive novel ideas and solutions. Similarly, a sudden spark for the clicking of novel ideas for some eminent thinkers also shows linkage with the ideosphere.

Many times when we think about the problem a sudden solution arises. This is probably because, after lots of deep thinking, our mind gets connected with the ideosphere in higher realms of cosmic consciousness. However due to wondering of our mind or its habit of being distracted this connection is short.

\section{Medium of thought transmission}

The question arises what is the medium through which novel ideas (thoughts) clicks in some people's mind or transmit from one to another place. The answer to this is that we live in an infinite flow of praña surrounding all which is also the eternal cause of viral energy. This is responsible for all types of actions and movements in nature. The existence of life is also due to this energy known as praña in Indian literature. The praña is omnipresent residing both within and outside of us. Its limitless expansion is a universe. Hence, everything including humans is subliminally linked with each other. The stimulated and intensified influx of praña makes the mind transmit or receive thoughts of the same nature and even transmit from one place to another place minds without any other medium. Thus praña itself acts as a medium too.

In his book on Yoga, Swami Abhedanand indicated that spiritually elevated persons and great yogis have the capacity to read others' minds. This is possible because their minds have the capacity to sense signals of praña and thoughts waves coming from other's minds and bodies.

Most of us have experienced the magnetic power of thoughts to attract thoughts of the same nature from compatible clusters. They intensify the collective effects. For example, criminals or sinners easily attract people with similar characters. Similarly, it is true that people with pure character and virtues like to work with the same nature resulting in a peaceful and positive environment. The refinement of the praña is very important. As per Dr. J. Monod, the human mind naturally tend to easily attract towards negative thoughts leading to untoward conduct whereas, purified praña as a result of refinement of personality though moral refinement of thoughts, creative activities, sympathy, etc leads to positive and subtle inspirations in person. Thus, it leads to the arousal of extrasensory potentials such as telepathic and cosmic communications (17). 


\section{An Article of Akhand Jyoti Magazine}

In another article of Akhand Jyoti published in February 1986, he quoted an article by Ardis Whitman from a renowned magazine called Reader's Digest. The title was "What is the limit of your mind?" Whiteman wrote in the article that keep the electricity and capacity of all-electric appliances on one side of the weigh and put 3 pints of grey matter from the brain on another side then the weight of the 3 pints of grey matter would be much more than the other side (18).

In the same article, Pandit Shriram has mentioned the main founder of psychical research known as King Croesus who was the king of Lydia from 560 B.C. to 546 B.C. He challenged seven famed oracles to tell his messengers exactly what he was doing on a given day. Only the Pythia, the priestess of Apollo at Delphi, answered correctly Croesus was making lamb and turtle stew in a bronze kettle. The tale may be apocryphal, and Croesus's misinterpretation of the oracle's advice eventually led to his defeat - but as an experiment, parapsychologists admit it wasn't bad.

The same article quotes a finding by Lyall Watson in his book named Supernature (19) in which Lyall has confirmed that telepathy is possible in plants which are even at the cellular level.

In the study of distant telepathy, he quotes a book by Douglas Dean titled Executive ESP (20). The study states that if some person sits at a faraway place and thinks deeply of a very close friend or relative the person who is being thought of starts feeling changes in the blood pressure, thought process, blood flow, heartbeats and breathing rates.

Pandit Shriram Ji also wrote around 108 huge volumes on varied topics out of this only All World Gayatri Parivaar has yet been able to publish only 70 of them. In the 18th Volume titled "Chatmakaari Visheshtao Se Bhara Manviya Mastishk", he mentioned the logic behind telepathy (21).

He writes that each thought is in a form of energy. The form of energy is bio-electromagnetic energy that if gathered with praña can manifest itself in the form that is intended. Swami Vivekanand in his thoughts on Raja Yoga mentioned, "Suppose, for instance, a man understood the Praña perfectly, and could control it, what power on earth would not be his? He would be able to move the sun and stars out of their places, to control everything in the universe, from the atoms to the biggest suns, because he would control the Praña. This is the end and aim of Prañayama. When the Yogi becomes perfect, there will be nothing in nature not under his control. If he orders the gods or the souls of the departed to come, they will come at his bidding. All the forces of nature will obey him as slaves. When the ignorant see these powers of the Yogi, they call them the miracles" (22).

Pandit Shriram scientifically understands that energy is in the form of waves and vibrations. These waves can influence the atomic structure of any other matter or energy. When the mental energy generated through the thoughts are gathered and applied in one force at a time on a single object, the influence happens. It can be observable or negligible but the possibility of influence cannot be ignored. Pandit Shriram Ji said that with various techniques one could increase the capacity to influence the matter or energy of any other object. These techniques have been mentioned in various spiritual texts and sects. Pandit Shriram Ji also invented several techniques to increase the bio-electromagnetic energy of an individual, which is an unexplored area of research. 


\section{SPIRITUAL PRACTICES AND SELF- REFINEMENT}

Pandit Shriram Sharmaji's literature can be considered an authority and an authentic source to understand the concepts of telepathy. The reason is the scientific shreds of evidence that the texts provide along with the real-life instances that people knowing Acharyaji have experienced. Several people have experienced that Acharyaji had supernatural capacities, which he has admitted at several instances of life. The text can be considered as an authentic source because he has practiced all the methods he has shown in the texts to increase and control the levels of praña. The spiritual techniques that he mentioned can be classified into three categories:

\section{Upasana}

With Upasana, Acharyaji conveyed the meaning to sit near the deity or the personality that one idolizes. In a way, one should sit quietly and perform meditation on the good qualities that prevail in the world. The best way to do this is to recite or chant a mantra along with some regimes that are applicable for the stability of the mind and body.

\section{Saadhna}

Saadhna, literally means to acquire control. Here Acharya Ji signifies 4 major restraints for spiritual development. These 4 major restraints are control of thoughts, speech, spending money and time. As per Acharyaji, if these four controls can be practiced in day to day life, one can acquire remarkable capacities if practiced consistently.

\section{Aaradhna}

With aaradhna, Acharya Ji has conveyed a sense of service. As per him, the Ego is the biggest tool to make the person void of any capacities. The downfall of any person begins with ego. To resolve this 'Ahamkaar' Acharya Ji has given an idea that is to serve the society. There are different ways he has suggested to practice Aaradhna. One can donate his/her time, skills, money or compassion for the betterment of society, which can ultimately lead to social well-being. Any act done selflessly for the welfare of society can be called Aaradhna.

Thus practicing the USA (Upasana, Saadhna \& Aaradhna) model of Pandit Shriram Sharma Acharya, one can acquire capacities that can be considered as supernatural, provided the practice of them is done consistently and consciously. More research is possible in this area where one can study various techniques of Upasana and understand its effect on the capacity of telepathy. Yoga and Prañayama can also be ways to enhance the supernatural capacities but with deeper practice.

\section{CONCLUSION}

Indian ancient literature is filled with resources that seem miraculous at a superficial view with limited understanding. However, with a deep analysis of laws of nature and science along with experiential guidance and reading, one can understand that concept of Telepathy and extrasensory potential has a basis that requires proper scientific attention and investigation through understanding the requirement of enhancing such potential with spiritual practices in essence. The only lacuna is the intensity and clarity to practice this science.

Funding: The author declared no specific grant for this research from any funding body i.e. public, commercial or not-for-profit sectors, etc.

Competing interests: None declared.

Patient consent for publication: Not required. 


\section{REFERENCES}

1. Jessica Gasiorek. Message Processing: The Science of Creating Understanding. University of Hawai'i OER. Available from http://pressbooksdev.oer.hawaii.edu/messageprocessing/chapter/chapter4-communicative-codes/

2. Rupert Sheldrake and Pamela Smart. A Dog That Seems To Know When His Owner is Coming Home: Videotaped Experiments and Observations. Journal of Scientific Exploration. 2000;14:233-255.

3. William Joseph Long. How Animals Talk And Other Pleasant Studies Of Birds And Beasts (1919). 2008. Kessinger Publishing, LLC.

4. Kirschvink, Joseph L. Earthquake Prediction by Animals: Evolution and Sensory Perception, Bull. Seism. Soc. Am.. 2000;90:312-323. https://doi.org/10.1785/0119980114

5. Yogananda. Autobiography of a Yogi. 12th ed., 12th paperbound printing. Los Angeles, Calif.: SelfRealization Fellowship, 1993.

6. Hamilton, Trevor. Immortal Longings: FWH Myers and the Victorian Search for Life After Death. Imprintacademic.com, 2009.

7. Bernardo Kastrup. Decoding Jung's Metaphysics: The Archetypal Semantics of an Experiential Universe. 2021

8. Luckhurst, R.. The Invention of Telepathy, 1870-1901. Oxford University Press, 2002.

9. Storm, Lance. Meta-analysis in parapsychology: II. Psi domains other than ganzfeld. Australian Journal of Parapsychology. 2006;6:135-155.

10. Glossary. Parapsychological Association - Affiliate of AAAS.

https://web.archive.org/web/20101006075546/http://para psych.org/glossary_s_z.html

11. Plazo, Joseph R.. Psychic Seduction. 2002:112-114. ISBN 0-9785922-3-9

12. 4.St. Claire, David. Instant ESP. 1989:40-50

13. Chris Carter, Science and Psychic Phenomena: The Fall of the House of Skeptics, Inner Traditions, 2012
14. Stadler, M. Wolfgang Metzger. Psychol. Res. 1980;42:191-193. https://doi.org/10.1007/BF00308526. https://doi.org/10.1007/BF00308526

15. Palmer, John. "ESP in the Ganzfeld". Journal of Consciousness Studies. 2003;10:6-7.

16. Ullman, Montague \& Krippner, Stanley. An Experimental Approach to Dreams and Telepathy: II. Report of Three Studies. The American journal of psychiatry. 1970;126:1282-9.

https://doi.org/10.1176/ajp.126.9.1282

17. Pandit Shriram Sharma Acharya, Extra Sensory Potentials of Mind, Shantikunj - Haridwar, 1996.

18. Pandit Shriram Sharma Acharya (Editor). Vigyan Sammat Vichar - Sampreshan Vidha. Akhannd Jyoti. 1986;02:33.http://literature.awgp.org/akhandjyoti/1986/F ebruary/v1.33

19. Lyall Watson. Supernature. 1973 Hodder \& Stoughton Ltd. ISBN 9780340173688 ISBN10: 0340173688.

20. Douglas Dean. Executive ESP. Prentice-Hall, 1974. ISBN, 0132941813, 9780132941815.

21. Pandit Shriram Sharma Acharya. Chatmakaari Visheshtao Se Bhara Manviya Mastishk. Revised edition, Shantikunj Haridwar, 2000.

22. Vivekananda, Swami. Rāja-yoga. New York: Ramakrishna-Vivekananda Center, 1986. Print. 